ARTICLE

DOI: $10.1038 / \mathrm{s} 41467-017-00200-8$

OPEN

\title{
Long-term hepatitis B infection in a scalable hepatic co-culture system
}

Benjamin Y. Winer ${ }^{1}$, Tiffany S. Huang ${ }^{1}$, Eitan Pludwinski ${ }^{2}$, Brigitte Heller ${ }^{1}$, Felix Wojcik ${ }^{3}$, Gabriel E. Lipkowitz ${ }^{1}$ Amit Parekh², Cheul Cho ${ }^{2}$, Anil Shrirao ${ }^{2}$, Tom W. Muir ${ }^{3}$, Eric Novik ${ }^{2}$ \& Alexander Ploss ${ }^{1}$

Hepatitis B virus causes chronic infections in 250 million people worldwide. Chronic hepatitis $B$ virus carriers are at risk of developing fibrosis, cirrhosis, and hepatocellular carcinoma. A prophylactic vaccine exists and currently available antivirals can suppress but rarely cure chronic infections. The study of hepatitis B virus and development of curative antivirals are hampered by a scarcity of models that mimic infection in a physiologically relevant, cellular context. Here, we show that cell-culture and patient-derived hepatitis B virus can establish persistent infection for over 30 days in a self-assembling, primary hepatocyte co-culture system. Importantly, infection can be established without antiviral immune suppression, and susceptibility is not donor dependent. The platform is scalable to microwell formats, and we provide proof-of-concept for its use in testing entry inhibitors and antiviral compounds.

\footnotetext{
${ }^{1}$ Department of Molecular Biology, Princeton University, Princeton, NJ 08544, USA. ${ }^{2}$ Hurel ${ }^{\circledR}$ Corporation, North Brunswick, NJ 08902, USA. ${ }^{3}$ Department of Chemistry, Princeton University, Princeton, NJ 08544, USA. Correspondence and requests for materials should be addressed to

A.P. (email: aploss@princeton.edu)
} 
epatitis $\mathrm{B}$ virus (HBV) belongs to the Hepadnaviridae family and has a very compact, partially double-stranded $3.2 \mathrm{~kb}$ DNA genome known as relaxed circular DNA (rcDNA). HBV entry is dependent on the bile acid transporter human sodium-taurocholate cotransporting polypeptide (hNTCP), which is exclusively expressed in hepatocytes 1,2 . Interaction of HBV surface antigen (HBsAg) with NTCP initiates uptake, during which the virus is internalized via receptormediated endocytosis (reviewed in ref. ${ }^{3}$ ). Following uncoating, $\mathrm{HBV}$ rcDNA is transported and released into the nucleus. The rcDNA contains several DNA lesions and hijacks the liver DNA repair system to form a stable HBV DNA molecule ${ }^{4,5}$. This DNA molecule is referred to as covalently closed circular DNA (cccDNA). cccDNA is a chromatinized "mini-chromosome" and serves as the transcriptional template for all four viral gene products-envelope (L, M, and S), core and X antigens (Ags) and the viral polymerase-as well as the pgRNA (pre-genomic RNA). pgRNA can be reverse transcribed into rcDNA, which can be enclosed by a lipid bilayer containing the HBV envelope proteins and then released from the host cell, thereby completing the HBV life cycle ${ }^{6}$.

HBV cccDNA is the cause of persistent HBV infection and subsequent severe liver disease, including hepatocellular carcinoma (HCC). In order to prevent HCC, it is imperative to purge or at least effectively silence cccDNA. Unfortunately, despite decadelong efforts, fundamental aspects of how cccDNA is formed, maintained and transcriptionally regulated remain opaque. Antivirals to cure chronic $\mathrm{HBV}$, such as those that target cccDNA, have not been successfully generated. Development of such curative therapies has been hampered by the scarcity of experimental systems that recapitulate the chronic phase of the infection.

HBV has a narrow tissue and host tropism limited to productive infections in human and chimpanzee hepatocytes, posing challenges for the study of $\mathrm{HBV}$ in experimental models ${ }^{4}$. Transfection of plasmids encoding larger-than-genome-size HBV sequences into human hepatoma cells has facilitated the study of some aspects of the HBV life cycle ${ }^{7,8}$. However, as an artificial system and not a bona fide infection, critical steps of the viral life cycle are not faithfully recapitulated. Other work has shown that specific cell lines derived from human HCCs, such as HepaRG cells, are susceptible to $\mathrm{HBV}^{9}$. The panel of cell lines that can be infected with HBV was substantially expanded after the identification of human NTCP, also known as SLC10A1, as a functional receptor for HBV and hepatitis delta virus (HDV) $)^{1,2}$. Indeed, ectopic expression of human NTCP is sufficient to increase permissiveness in a variety of immortalized liver cells ${ }^{1,2}$. Although experiments in hepatoma cell lines can be reproducible and inexpensive, these immortalized cells do not adequately recapitulate the physiological environment of primary hepatocytes due to their abnormal proliferation and aberrant gene regulation. For in vitro experiments, primary hepatocyte cultures are thus more desirable ${ }^{10}$. Previous work has indeed shown

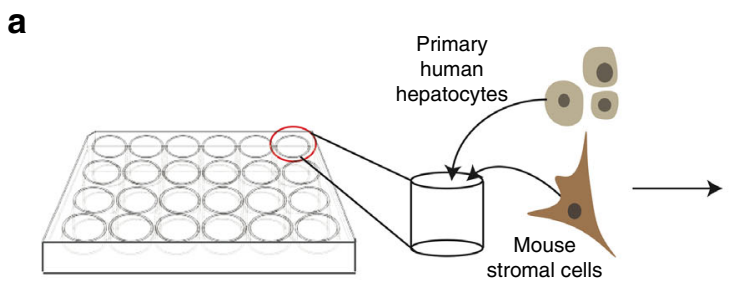

b
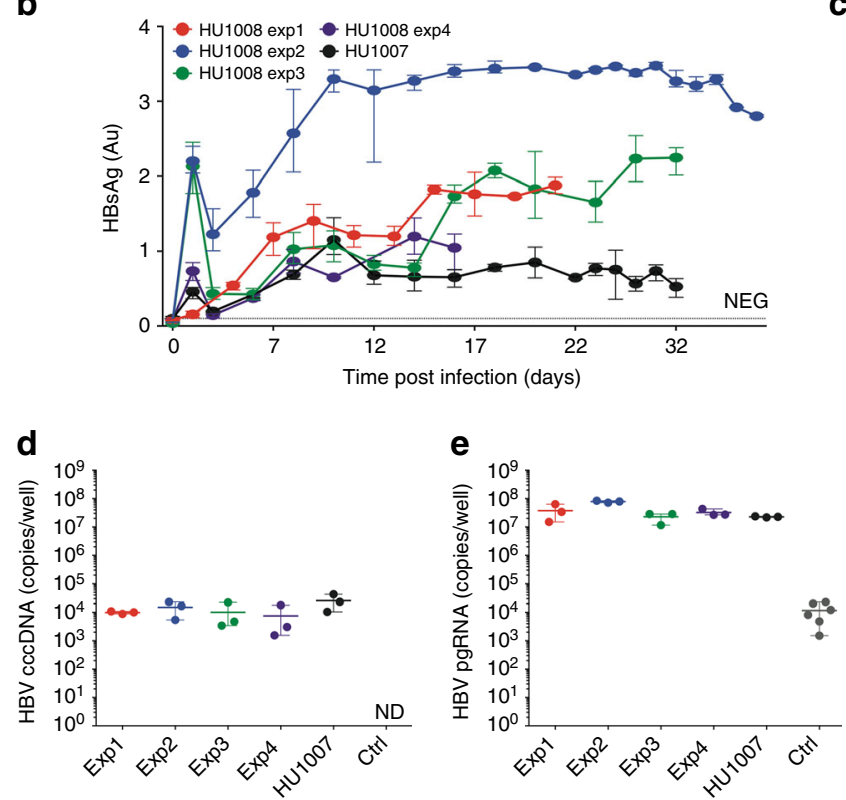

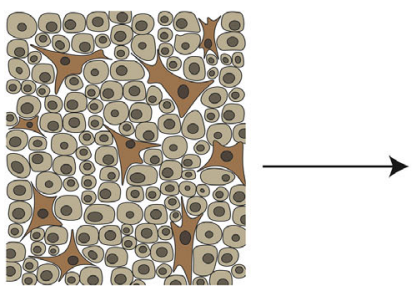

C

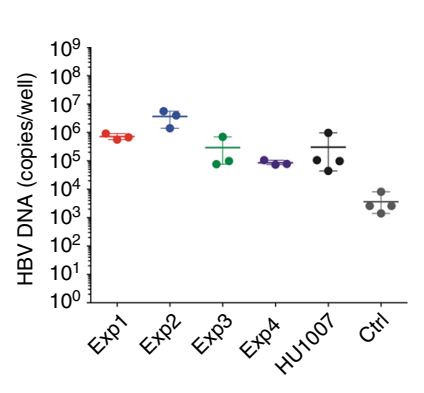

f

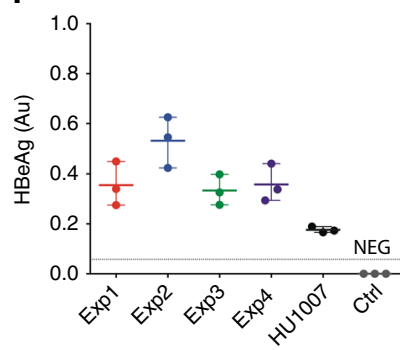

g

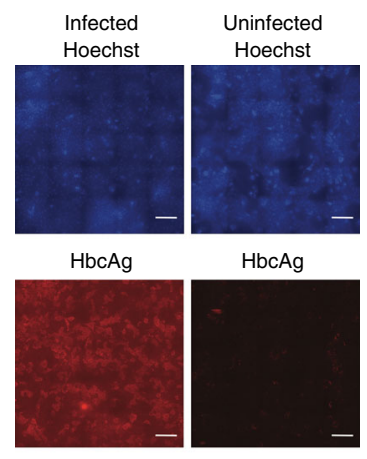

Mege

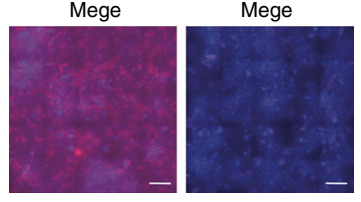

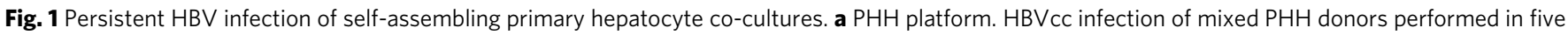
separate experiments with two separate lots of hepatocytes. HBsAg concentrations determined in the supernatants $\mathbf{b}$ and total HBV DNA c, HBV

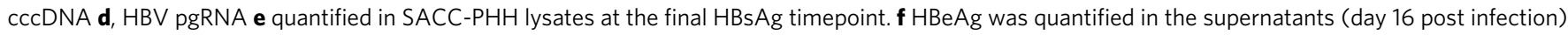
by HBeAg ELISA. g HBcAg detection in HBV-infected (left panels) and non-infected (right panels) mixed donor SACC-PHHs by immunofluorescence microscopy; $\mathrm{HBcAg}$ (red), nuclear Hoechst dye (blue), all scale bars are $200 \mu \mathrm{m}$. For all HBVcc infections of mixed PHH donors three to five biological replicates were performed. All data are presented as means \pm s.d 
a

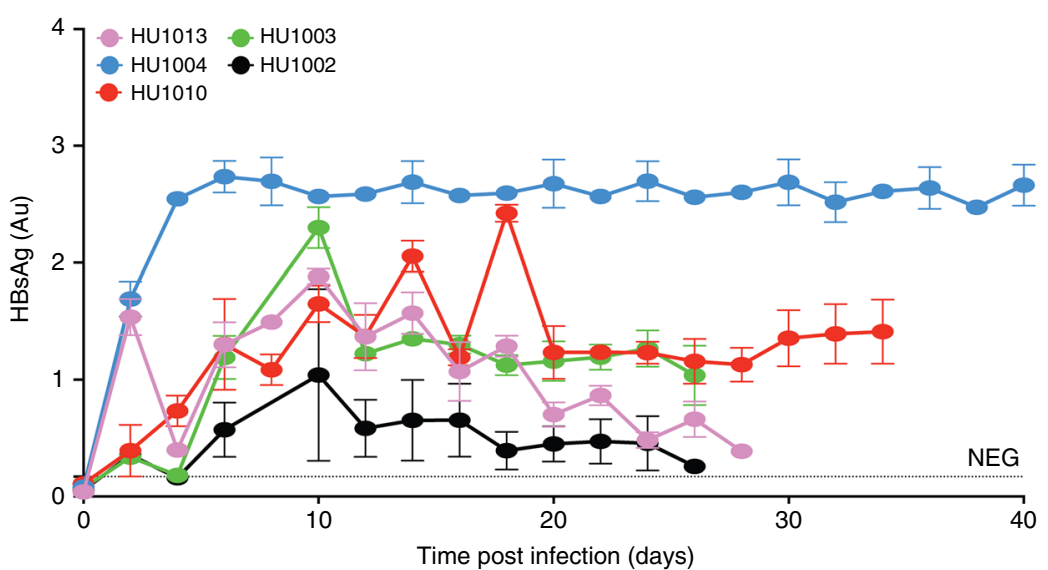

b

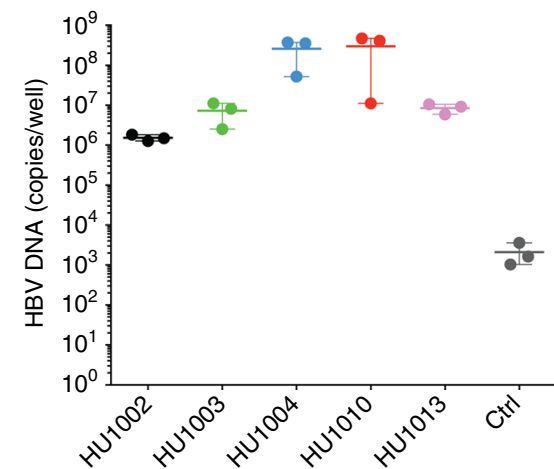

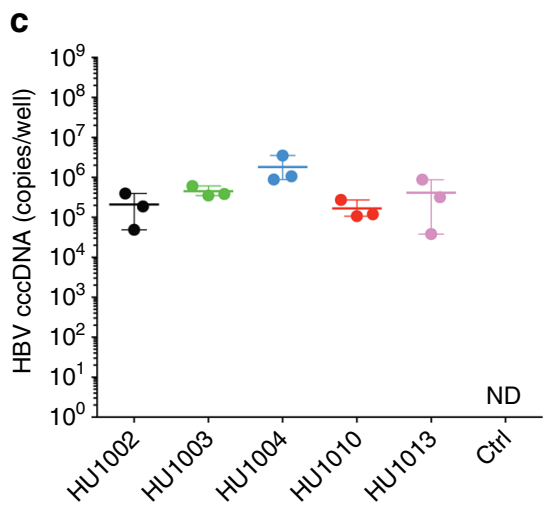
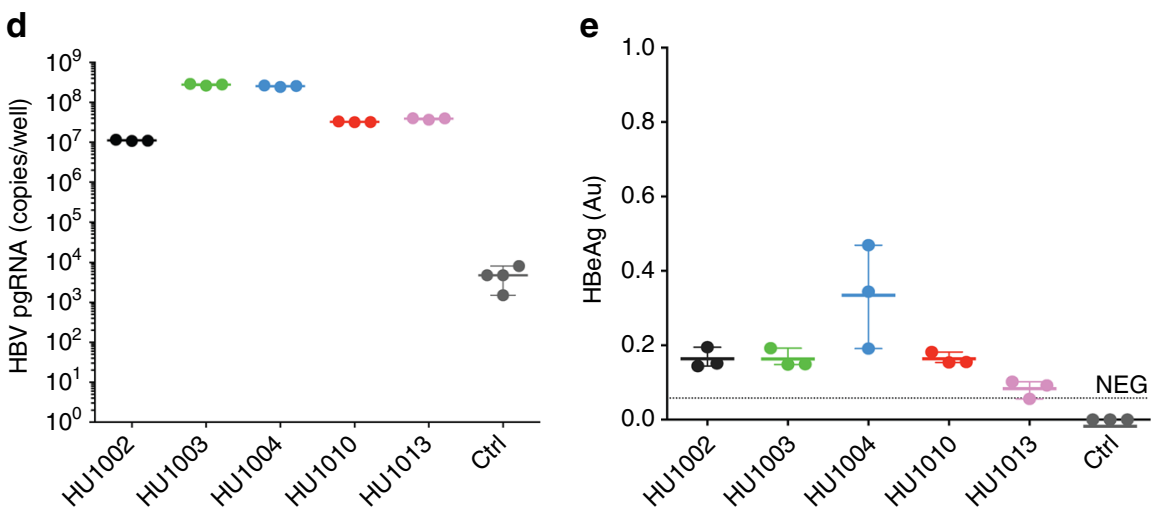

Fig. 2 Persistent HBV infection in single donor PHH co-cultures. Assessment of HBVcc infection of single donor SACC-PHH co-cultures. Quantification of $\mathrm{HBsAg}$ concentrations in the supernatants $\mathbf{a}$, and total HBV DNA b, ccCDNA c, pgRNA d in SACC-PHH lysates. e HBeAg was quantified in the supernatants (day 16 post infection) by HBeAg ELISA. For all HBVcc infections of single PHH donors three to five biological replicates were performed. All data are presented as means \pm s.d

that primary human hepatocytes (PHHs) of both adult and fetal origin can be infected with $\mathrm{HBV}^{11-16}$. However, long-term infections of PHHs with $\mathrm{HBV}$ or other hepatotropic pathogens, such as hepatitis $\mathrm{C}$ virus $(\mathrm{HCV})$ or parasites that cause malaria in humans, have been notoriously difficult due to their rapid dedifferentiation and loss of characteristic hepatic functions following isolation and plating. As a result, analyses of HBV's interactions with the host cell have been largely limited to the first few days following plating, reflecting only acute infection. $\mathrm{PHH}$ dedifferentiation can be delayed/prevented in collagen sandwich cultures, by aggregation in spheroids or in co-culture with non-parenchymal cells ${ }^{17,18}$. For the latter approach, both self-assembling (SACC) and micro-patterned $\mathrm{PHH}$ co-cultures (MPCC) are effective formats to stabilize hepatic function, especially if oxidative stress is reduced during the onset of the culture $^{19-21}$. MPCC of PHHs and murine 3T3 fibroblasts have been infected with $\mathrm{HBV}, \mathrm{HCV}$, and Plasmodium falciparum and vivax $^{22-24}$. However, in these studies, HBV infection was limited to a few donors and required suppression of antiviral signaling, posing problems for studying host responses to HBV for antiviral drug testing 22 .

Here, we aimed to carefully characterize HBV infection in SACC-PHHs in culture formats amenable to high-throughput analysis. We demonstrate that SACC-PHHs generated with pooled or single $\mathrm{PHH}$ donors but not $\mathrm{PHH}$ monocultures support persistent infection with cell-culture and patient derived HBV for more than 40 days. The platform can be miniaturized to 96-well plate formats in which uniform HBV infection can be achieved. Using this high-throughput platform, we show that a preS1- derived myristoylated peptide can efficiently prevent HBV uptake, which is consistent with previous findings in vitro ${ }^{25,26}$. Likewise, administration of a clinically approved inhibitor of the HBV polymerase, entecavir, suppressed HBV viremia in a dose-dependent fashion. In contrast, pharmacological inhibition of the host enzyme tyrosyl-DNA-phosphodiesterase 2 (TDP2), which has been implicated in a critical step prior to cccDNA formation $^{27}$, had no effect on HBV infection. Collectively, our data establish proof-of-concept for the utility of the SACC-PHH platform as a versatile, robust platform to study HBV persistence of genetically diverse viral isolates and for efficacy assessments of host-targeting and directly acting antivirals.

\section{Results}

Persistent HBV infection in SACC-PHHs. SACCs are established by plating PHHs (Supplementary Table 1) with non-parenchymal stromal cells in collagen-coated tissue culture plates (Fig. 1a) utilizing a protocol previously reported to promote advanced hepatic morphology, such as bile caniliculi formation, and to enhance numerous hepato-specific functions for extended culture periods (Supplementary Table 2) ${ }^{19,28-30}$.

To test susceptibility to HBV, SACC-PHHs were exposed to different amounts of purified, cell culture-derived HBV (HBVcc). $\mathrm{HBV}$ infection was considerably more robust in SACC-PHHs generated from pooled hepatocyte donors (donor characteristics summarized in Supplementary Tables 1 and 2) compared to a HepG2 cell clone (3B10) expressing high levels of hNTCP (Supplementary Fig. 1a-d) as evidenced by significantly greater 
a

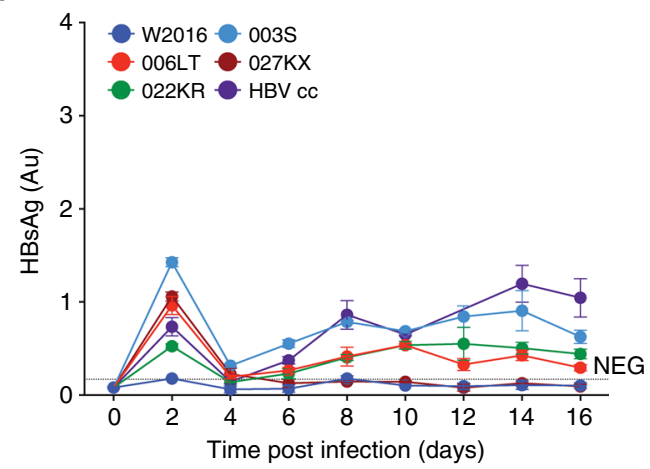

C

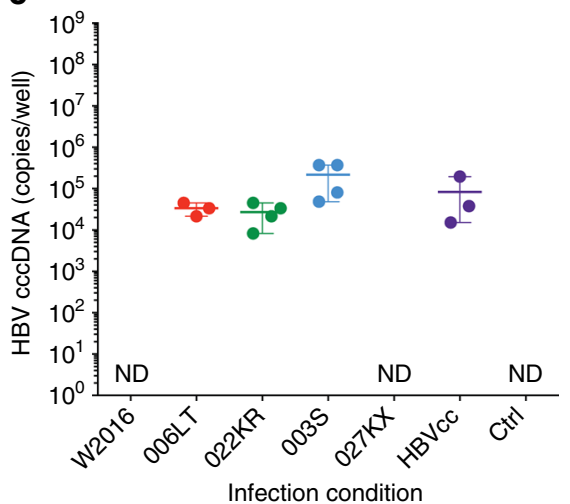

b

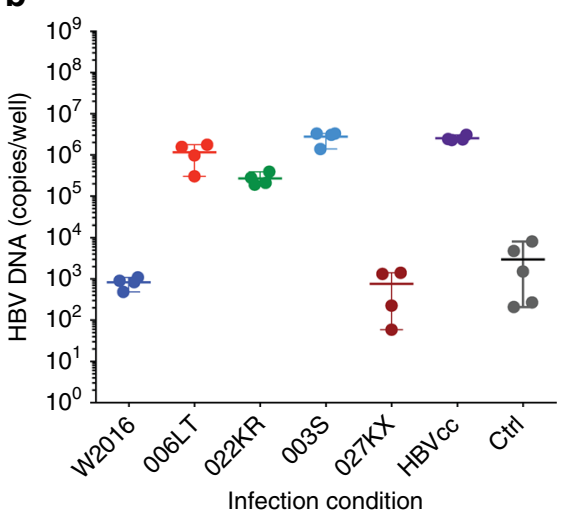

d

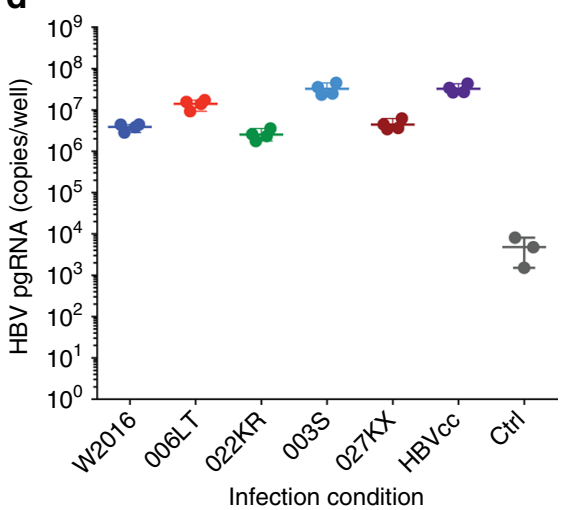

Fig. 3 Long-term persistent infection of SACC-PHHs with patient-derived HBV. Assessment of heparin column-purified HBVpat infection of mixed donor HU1008 SACC-PHHs. Quantification of HBsAg concentrations in the supernatants $\mathbf{a}$, and total HBV DNA $\mathbf{b}, \mathrm{cccDNA} \mathbf{c}$, and pgRNA d in SACC-PHH lysates. For all HBVpat infections of mixed donors four biological replicates were performed. All data are presented as means $\pm s . d$

secretion of HBsAg (Supplementary Fig. 2a, b). HBV infection was highly reproducible and not dependent on particular lots of pooled hepatocyte donors or batches of HBVcc inocula (Fig. 1b, c). Previous work found inhibition of Janus kinase (JAK)-dependent signaling necessary to establish HBVcc infection for up to 19 days in MPCCs ${ }^{22}$. In contrast, in SACC-PHHs, HBsAg secretion was sustained for more than 30 days postinfection without suppression of antiviral defenses (Fig. 1b). At the end point, HBV DNA (Fig. 1c), cccDNA (Fig. 1d, Supplementary Fig. 3) and HBV pgRNA (Fig. 1e) were readily detected in lysates of HBV-infected SACC-PHHs. The detection of $\mathrm{HBV}$ precore antigen ( $\mathrm{HBeAg}$ ) in the $\mathrm{HBV} \mathrm{cc}$-challenged samples provided additional evidence that cccDNA was formed and that active viral transcription was occurring from the cccDNA template (Fig. 1f) ${ }^{31}$. Immunofluorescent visualization of $\mathrm{HBV}$ core antigen $(\mathrm{HBcAg})$ demonstrated that the majority of hepatocytes in the culture were infected (Fig. $1 \mathrm{~g}$ ).

All infections were carried out between 7-10 days following plating at a point previously determined as optimal for restoring hepatic functions in the cultures $29,32,33$. To determine whether the time point of initial HBV infection could possibly be extended further, we challenged mixed donor SACC-PHHs with HBVcc 10, 15, or 20 days post-plating (schematic Supplementary Fig. 4a). We observed that the SACC-PHHs remained susceptible for all time points tested as indicated by HBsAg secretion. However, SACC-PHHs challenged at 10 and 15 days post seeding reached comparable levels of HBsAg 8 days after infection, cells that were challenged 20 days post seeding became infected but secreted substantially lower amounts of HBsAg indicative of a less efficient infection. This may indicate that either SACC-PHHs at day 20 post seeding became less susceptible to $\mathrm{HBV}$ infection or that transcriptional changes have occurred that affect HBsAg secretion (Supplementary Fig. 4b).

To determine whether the robustness of the platform was in part due to the use of pooled donor $\mathrm{PHH}$ lots, we analyzed HBVcc infection in SACC-PHHs established from five single donors. HBsAg was detectable shortly after inoculation of the cultures with $\mathrm{HBVCc}$ and was sustained for the duration of the experiment (Fig. 2a). HBV DNA (Fig. 2b), cccDNA (Fig. 2c, Supplementary Fig. 3) and pgRNA (Fig. 2d) reached levels similar to those in HBVCC-infected SACC-PHHs generated with pooled donor lots. In line with these observations, HBeAg was detectable in all infected samples and largely corresponded with secreted HBsAg levels (Fig. 2e). To affirm that the high permissiveness of the PHHs in co-culture is attributable to the culture format, we directly compared susceptibility of SACC-PHHs with PHHs of the same hepatocyte donor (HU1003). The morphology of the monoculture after plating showed the classic cobblestone pattern of healthy PHHs (Supplementary Fig. 5a, left), but by day eight morphological changes had occurred indicating de-differentiation and deterioration of the culture (Supplementary Fig. 5a, right). This loss of hepatocyte morphology also correlated with a decrease in hepatic functions as evidenced by the progressively lower levels of secreted albumin (Supplementary Fig. 5b). As expected, exposure of $\mathrm{PHH}$ monocultures to HBVcc thus did not yield any measurable evidence of infection, in stark contrast to the high HBV permissiveness of the hepatocytes in the SACC-PHH format (Supplementary Fig. 5c).

Persistent $\mathrm{HBV}$ infection using $\mathrm{HBV}$ patient isolates. $\mathrm{HBV}$ is a genetically diverse virus that has been classified into eight 
a

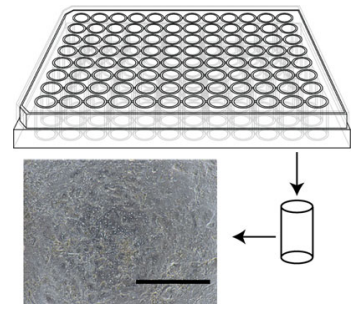

b

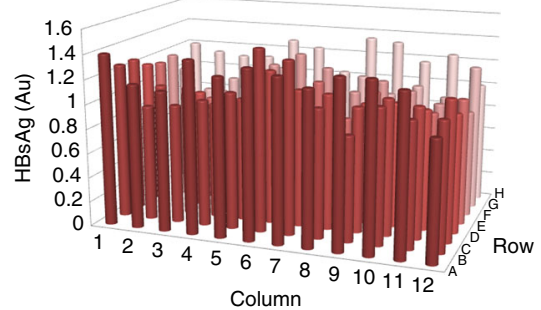

C

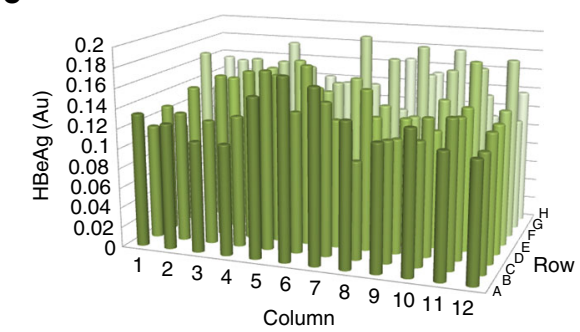

d

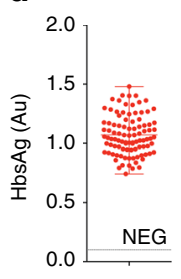

e

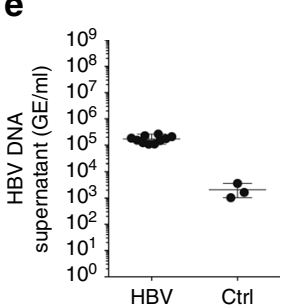

f

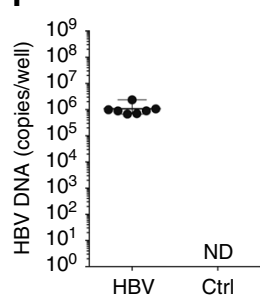

g

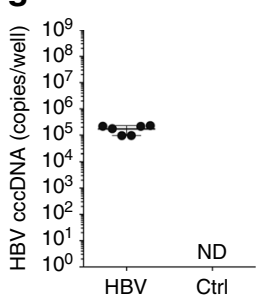

h

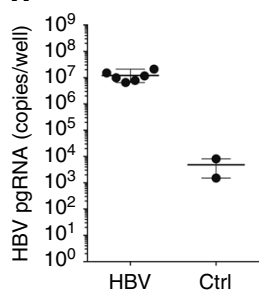

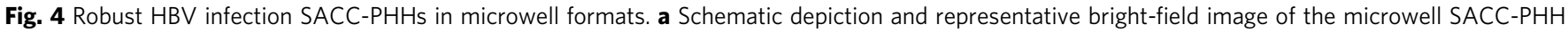
system (scale bar $=400 \mu \mathrm{m}$ ). Quantification of HBsAg b and HBeAg c across the 96-well format at 10 dpi (day 20 post seeding). d Limited variation of $\mathrm{HBsAg}$ (left, mean 1.070 Au, std $0.167 \mathrm{Au}$, two tail $t$-test $p$-value <0.0001, compared to $1 \mathrm{Au}$ ), HBeAg (middle, mean $0.142 \mathrm{Au}$, std $0.024 \mathrm{Au}$, two tail $t$-test $p$-value $<0.0001$, compared to $0 \mathrm{Au}$ ) and hAlb (right, mean $15.75 \mu \mathrm{gml}$ per $10^{6}$ cells per $24 \mathrm{~h}$, std $2.679 \mu \mathrm{gml}$ per $10^{6}$ cells per $24 \mathrm{~h}$, two tail t-test $p$-value $<0.001$, compared to $15 \mu \mathrm{gml}$ per $10^{6}$ cells per $24 \mathrm{~h}$ ) at $10 \mathrm{dpi}$. Quantification of HBV DNA in culture supernatants e at 10 dpi, and total HBV DNA f, cccDNA $\mathbf{g}$ and pgRNA $\mathbf{h}$ in cell lysates of randomly picked wells at 30 dpi. For HBV DNA and RNA quantifications six to ten replicates were performed. For $\mathrm{HBsAg}, \mathrm{HBeAg}$, and hAlb 96-biological replicates were performed. All data are presented as means \pm s.d

genotypes $(\mathrm{A}-\mathrm{H})$ and multiple sub-genotypes by means of molecular evolutionary analyses ${ }^{34-36}$. HBV within a given patient can harbor a variety of additional mutations, further increasing the viral diversity. Genetic variation of $\mathrm{HBV}$ has been linked to differences in disease severity, which is influenced by a variety of virologic parameters, including differences in replicative fitness and viral protein expression ${ }^{37}$. To better understand this genetic diversity, infections should optimally be established with patientderived viruses, which has proven difficult.

To determine whether infection of SACC-PHHs is limited to HBVcc, we infected the cultures with heparin column-purified, patient-derived HBV (HBVpat) (Supplementary Fig. 6a, b). While exposure of $3 \mathrm{~B} 10$ cells to HBVpat led to no productive infection (Supplementary Fig. 6c-f), HBV from 3/5 patients resulted in infection levels similar to those reached with HBVcc as assessed by HBsAg enzyme-linked immunosorbent assay (ELISA) (Fig. 3a). Consistent with the rise in HBsAg levels, HBV DNA (Fig. 3b), cccDNA (Fig. 3c, Supplementary Fig. 3) and pgRNA (Fig. 3d) were higher in SACC-PHHs as compared to challenged 3B10 cells and non-infected controls (Supplementary Fig. 6c-f).

HBV infection in microscale hepatocyte culture formats. Having established robust and persistent $\mathrm{HBV}$ infections in a 24-well format, we then aimed to determine whether the platform could be scaled to a format amenable to high throughput screening (HTS) applications. SACC-PHHs prepared with hepatocytes from a pooled donor were established in 96-microwell plates (Fig. 4a) and exposed to HBVcc 10 days following infection, HBsAg, HBeAg and human albumin, with the latter serving as a marker of cellular functionality, were secreted uniformly with minimal variation (coefficient of variation for $\mathrm{HBsAg}=15.57 \%$, $\mathrm{HBeAg}=16.61 \%$, human albumin $(\mathrm{hAlb})=17.58 \%)$ across the entire plate (Fig. $4 \mathrm{~b}-\mathrm{d}$ ). As further evidence for a productive $\mathrm{HBV}$ infection, we quantified HBV DNA in supernatants (Fig. 4e) and cell lysates (Fig. 4f), along with cccDNA (Fig. 4g), and pgRNA (Fig. $4 \mathrm{~h}$ ) in wells randomly chosen across the plate. Increases in all these parameters demonstrated that SACC-PHHs in the HTS format were robustly infected.

Inhibition of viral entry using $\mathrm{HBV}$ preS1-derived peptides. HBV utilizes the bile-acid transporter NTCP to enter hepatocytes (Fig. 5a) ${ }^{1,2}$ This process is-in part-facilitated through the physical interaction of the myristoylated first 48 amino acids of the large HBsAg with amino acids $157-165$ of $\mathrm{NTCP}^{38}$. It was previously shown that acylated peptides derived from the large HBsAg can block virus entry in vitro ${ }^{25}$ and in human liver chimeric mouse models ${ }^{26}$. Here, we aimed to establish proof-ofconcept for the utility of the SACC-PHH platform to test such entry inhibitors. HBVcc was pre-incubated with different amounts of $\mathrm{HBV}$ preS $/ 2-48^{\mathrm{myr}}$ or a control peptide in which the NTCP binding domain was substituted with a quintuple alanine sequence in positions 10-14, abolishing the ability of the peptide to inhibit HBV infection ${ }^{38}$. Following infection and removal of the inoculum, peptides were added at the appropriate concentrations to the media. In line with previous studies, the HBV preS1-derived peptide efficiently blocked HBV infection in the SACC-PHH cultures, whereas the control peptide had no effect (Fig. 5b).

Pharmacologic TDP2 inhibition does not suppress HBV viremia. Next, we tested the relative efficacy of various direct-acting antivirals (DAAs) and putative host-targeting antivirals (HTAs) to suppress HBV viremia in the HTS format. Entecavir (ETV, Baraclude) is an inhibitor of HBV reverse transcriptase (RT) that is widely used in clinical practice (Fig. 5a). Recent biochemical data implicated TDP2 as a candidate enzyme for removal of the RT from rcDNA in a step crucial for cccDNA formation (Fig. 5a $)^{27}$. However, a follow up in vitro study showed only a minor impact of knock-down or knock-out of TDP2 on cccDNA formation in hepatoma cells, suggesting other redundant enzymes are likely involved in catalyzing RT removal ${ }^{39}$. To test the effect of pharmacologic inhibition on HBV infection, we utilized two 
a

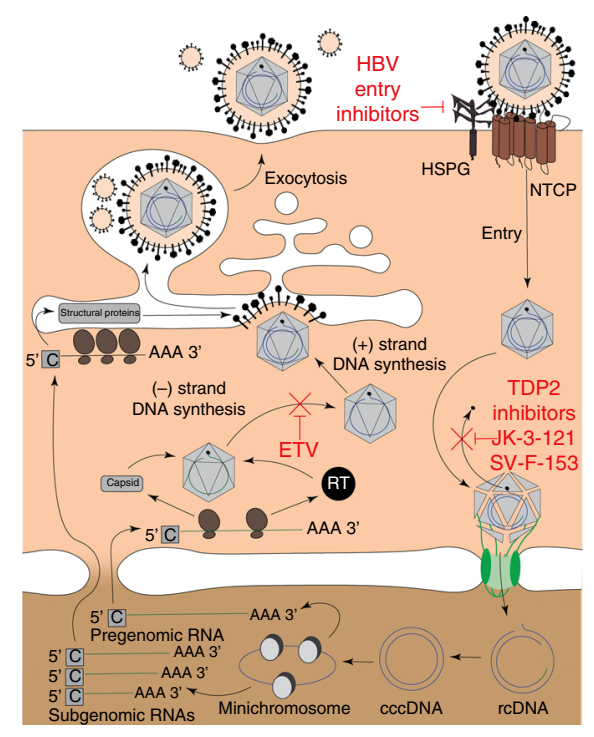

c

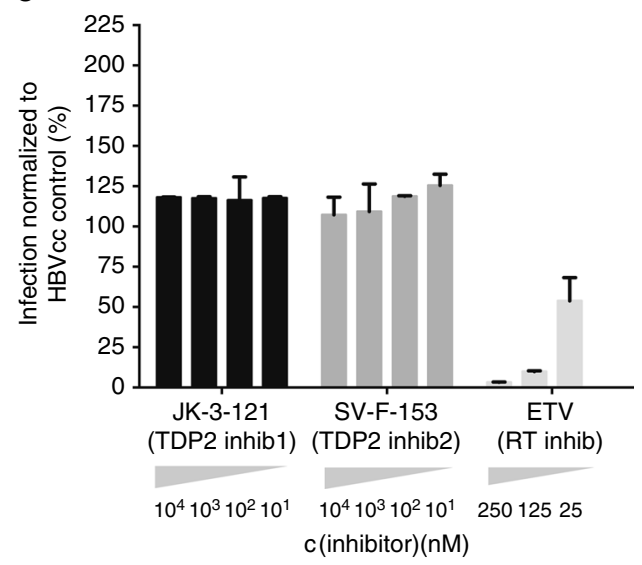

b

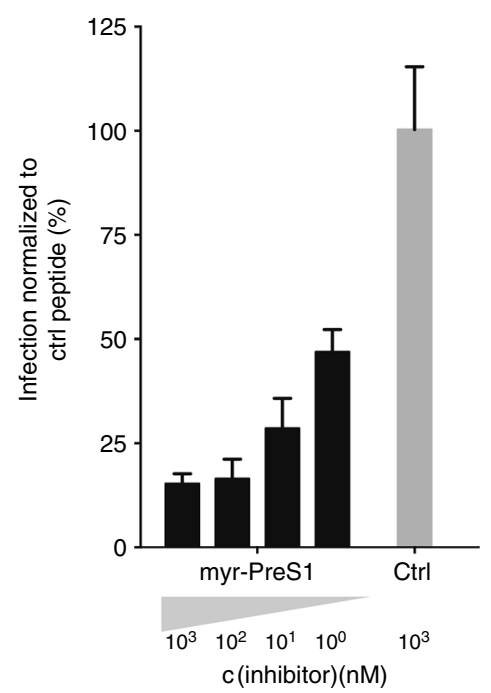

d

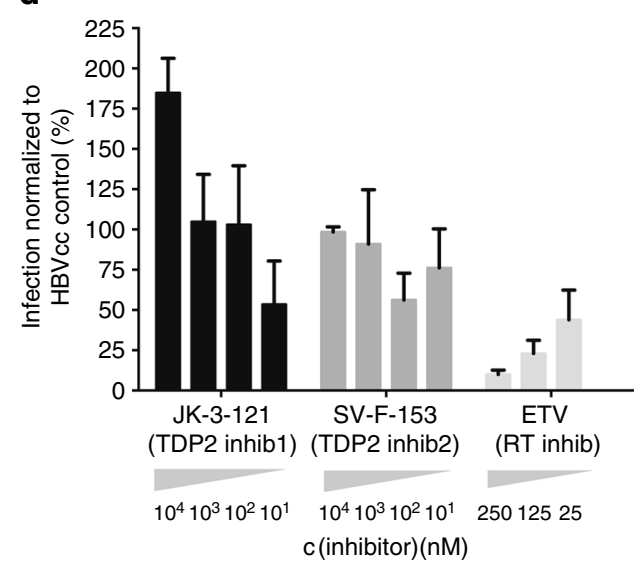

Fig. 5 Utility of SACC-PHHs for antiviral drug testing. a Schematic of HBV life cycle indicating the presumed mechanism of action of myr-PreS1 entry inhibitor, TDP2 inhibitors and ETV. b Prophylactic treatment with myr-preS1-derived peptides in SACC-PHH 96-well format (HU1007 mixed donor). Prophylactic $\mathbf{c}$ and therapeutic $\mathbf{d}$ drug dosing of SACC-PHHs (mixed donor HU1008) in 96-well format for nucleotide analog ETV and TDP2 inhibitors (JK-3-121, SV-F-153), $x$-axis: concentration of different drugs. $y$-axis: amount of HBsAg secretion normalized to that secreted by HBVcc infected untreated control cells. For $\mathrm{HBV} c \mathrm{infections}$ and drug treatments, six biological replicates were performed. All data are presented as means $\pm \mathrm{s} . \mathrm{d}$

small molecules (JK-3-121 and SV-F-153, Supplementary Fig. 7a) previously shown to efficiently suppress the activity of human TDP2 with high selectivity ${ }^{40}$. To corroborate that JK-3-121 and SV-F-153 indeed had an inhibitory effect on this enzyme, we produced recombinant human TDP2 in E. coli (Supplementary Fig. 7b). Following established protocols, we obtained high yields of hTDP2, which was purified by nickel affinity column size exclusion chromatography (Supplementary Fig. 7c) ${ }^{40}$. hTDP2 has $\mathrm{Mg}^{2+}$-dependent activity on $5^{\prime}$-phosphotyrosylated $\left(5^{\prime}-\mathrm{Y}\right)$ termini of single-stranded DNA or on duplex substrates with $5^{\prime}$ overhangs of one to four nucleotides and is thought to be involved in the removal of the viral polymerase from HBV rcDNA (Supplementary Fig. 7d). To validate that JK-3-121 and SV-F-153 effectively inhibit the enzymatic activity of TDP2, we employed an assay reported for TDP2 activity on a synthetic substrate, in which methylumbelliferon (MU), a Tyr mimic, is attached via a phosphodiester bond to the $5^{\prime}$-end of a 14-mer DNA oligo corresponding to the $5^{\prime}$-end of duck HBV (-) strand DNA (MUP-DNA) (Supplementary Fig. 7e) ${ }^{27}$. Incubation of TDP2 with MUP-DNA results in cleavage of the phosphotyrosyl bond, releasing fluorescent MU from nonfluorescent MUP-DNA, which can be monitored in real time using a fluorescence reader. Addition of JK-3-121 and SV-F-153 effectively inhibit this process, thus confirming the efficacy of these compounds (Supplementary Fig. $7 \mathrm{f})^{40}$.

ETV administration led to a reduction in $\mathrm{HBsAg}$ secretion in a dose-dependent fashion, both when supplied prophylactically, i.e., prior to infection (Fig. 5c; Supplementary Fig. 8a), or therapeutically (Fig. 5d). In contrast, inhibition of TDP2 had no effect on HBV infection in either setting (Fig. 5c, d; Supplementary Fig. 8b, c). Of note, results from equivalent drug dosing experiments in 3B10 cells were considerably more variable (Supplementary Fig. 8d, e), showing the utility of SACC-PHHs over the current system. The SACC-PHHs remained healthy, as indicated by hAlb levels, in both pharmacological inhibition settings (Supplementary Fig. 8f, g).

\section{Discussion}

Study of human hepatotropic pathogens has been historically difficult due to the scarcity of experimental models. HBV is a 
prime example of such a pathogen, which almost exclusively infects human hepatocytes. Numerous attempts have been undertaken to establish HBV infection in PHHs with highly varying efficiency (reviewed in ref. ${ }^{17}$ ), with none successful in microscale formats. Fetal human hepatocytes (FHHs) and human hepatocyte-like cells (HLCs) derived from induced pluripotent stem cells (iPSCs) have also been shown to be susceptible to HBV infection, but neither exhibits the fully mature adult $\mathrm{PHH}$

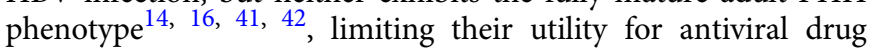
screening. Furthermore, while HLCs can be produced in unlimited quantities through directed differentiation of iPSCs, few FHHs can be isolated from a single donor, increasing interexperimental variability. Hepatocyte monocultures remain the gold standard, but in most studies, viral infections are abortive due to the rapid loss of hepatic functions ${ }^{13,15}$. More recent efforts have focused on sophisticated tissue engineering approaches employing co-cultures of $\mathrm{PHH}$ and non-parenchymal cells to stabilize the hepatic phenotype ${ }^{43}$, 44 . In a previous study, HBV was able to infect PHHs in MPCCs, but infection required JAK inhibition, was limited to specific hepatocyte lots and ceased within 14-19 days post infection ${ }^{22}$. While the severity of chronic hepatitis B has been linked to candidate alleles in genome-wide association studies, there is no evidence for widespread resistance to HBV infection, and thus almost any high-quality hepatocyte donor lot should be permissive to HBV infection ${ }^{45}$, 46 . Furthermore, HBV is considered a "stealth" virus that does not strongly induce cell-intrinsic antiviral defense pathways. Based on infection of chimpanzees and humanized mice, it should not be necessary to suppress antiviral signaling ${ }^{47}$. The SACC-PHHs described here enable bona fide HBV persistence beyond 30 days of infection.

Here, we demonstrated that cells in this culture format are susceptible to HBVcc. Between SACCs generated with pooled or single donors, we observed minor differences in the quantity of cccDNA and pgRNA (Figs 1d, e and 2c, d). While hepatocytes from each donor are mixed in equivalent proportions in the pooled lots, this may not necessarily translate to equal representation of each donor after plating. It is also conceivable that some of the donors in the pooled lots are less susceptible to HBV or the highly susceptible donors are underrepresented due to the above-mentioned differences in plating efficiency. In combination, these factors may explain the differences in the quantities of certain HBV replication intermediates. SACC-PHHs can also be infected with patient-derived viruses, which opens the possibility of studying genetically diverse viruses. Three out of five of the HBVpat samples led to robust, persistent infection while the remaining two failed to infect either SACC-PHHs or 3B10 cells. This is likely due to varying numbers of infectious particles in the preparation and the presence of neutralizing antibodies. Co-culture of PHHs with the stromal cells stabilized the hepatic phenotype, which was ultimately responsible for the high permissiveness to HBV. In contrast, our experimental hepatocyte monocultures rapidly deteriorated within 8 to 9 days post seeding and were consequently insusceptible or only minimally susceptible to HBV, even when exposed to the virus shortly after seeding. In contrast, robust infection could be established in the SAC-PHH format as late as 15 days following plating, giving greater flexibility in experimental design, e.g., for genetic manipulations prior to viral infection.

We also established proof-of-concept for the utility of this platform for antiviral drug testing using both DAAs and HTAs. Inhibition of HBV glycoprotein-mediated entry is being pursued as a therapeutic approach to prevent $\mathrm{HBV}$ infection, such as after liver transplantation, and might also restrain virus spread in chronically infected patients. In line with previous results obtained in HBV permissive lines and human liver chimeric mice $^{1,9,48-50}$, we validated that a preS1-derived peptide can efficiently interfere with HBV uptake into PHHs in the SACC platform. Administration of the candidate entry inhibitor, Myrcludex B, which is a preS1-derived peptide, has been shown to efficiently deplete nuclear cccDNA in humanized mice by preventing HBV reinfection ${ }^{50}$. Blocking viral entry with Myrcludex B can also suppress HDV, a small viroid that hijacks the HBV envelope, in patients persistently infected with HBV and HDV ${ }^{51,52}$. Thus, the SACC-PHH platform may have utility for assessing preclinically the efficacy of other entry inhibitors and possibly (vaccine-induced) neutralizing antibodies.

Inhibitors of the HBV RT are widely used to suppress HBV viremia in patients and also lead to a dose-dependent reduction in HBV infection in the SACC-PHHs in the 96-microwell format. To achieve a (functional) cure for chronic hepatitis B, elimination or permanent inactivation of cccDNA remains a priority. Biochemical data implicated TDP2 in the removal of the covalently attached RT from the incoming rcDNA, a crucial step preceding the formation of $\operatorname{cccDNA}^{27}$. However, genetic disruption of TDP2 did not lead to a reduction in HBV viremia ${ }^{39}$, suggesting redundancy in the presumed host enzymes that can facilitate RT removal. We provide evidence that pharmacologic inhibition of TDP2 is insufficient to suppress HBV viremia, which is consistent with previous genetic studies ${ }^{39}$. Numerous alternative approaches are being pursued targeting HBV cccDNA, and the SACC-PHH platform presented here may aid in the identification and testing of novel therapeutic regimens.

\section{Methods}

Cell lines. In all, 293 T (American Tissue Culture Collection, ATCC ${ }^{\circledR}$ Number: CRL-3216 ${ }^{\mathrm{TM}}$, Manassas, VA) and HepG2 cells (American Tissue Culture Collection, ATCC ${ }^{\circledR}$ Number: HB-8065 ${ }^{\mathrm{m}}$, Manassas, VA) were maintained in Dulbecco's modified Eagle medium (DMEM; ThermoFischer, Waltham, MA) base medium supplemented with $10 \%$ (vol/vol) fetal bovine serum. HepG2.2.15 cells ${ }^{7}$ (kindly provided by Dr Christoph Seeger, Fox Chase Center) were maintained in DMEM/10\% FBS media containing tetracycline (Sigma Aldrich, St Louis, MO) at $10 \mu \mathrm{g} / \mathrm{ml} .293 \mathrm{~T}$ cells were grown on tissue culture-treated plastic ware (Corning Inc., Corning, NY) and HepG2 and HepG2.2.15 cells on type IV collagen-coated plates (Sigma Aldrich, St Louis, MO).

Generation of human NTCP expressing HepG2 Cells. The hNTCP-eGFP lentiviral vector was generated as follows. A hNTCP-eGFP fusion protein was created by overlap PCR. In the first round of PCR: Round 1, Reaction 1: hNTCP was amplified from pCMV-Sport6 Slc10A1 hNTCP (OpenBiosystems, now Dharmacon, Lafayette $\mathrm{CO}$ ) with primers introducing flanking $5^{\prime} \mathrm{XbaI}$ site, $5^{\prime}$ Kozak sequence and $5^{\prime}$ FLAG to the hNTCP ORF, as well as a $3^{\prime}$ linker sequence (GGCAGC) and overlap fragment from the eGFP coding sequence. Round 1, Reaction 2: eGFP was PCR amplified from pShuttleCMV-eGFP (Addgene catalog \#16403) (previously functionally characterized version of eGFP) to introduce $5^{\prime}$ overhang of overlapping end of hNTCP ORF and linker sequence, and 3' Xhol site. In the second round of overlap PCR, the two products from the first round of PCR (modified hNTCP and modified eGFP) were use as template with the external primers to yield the final PCR product: XbaI-KOZAK-FLAG-hNTCP(GGCAG Clinker)eGFP-XhoI. This PCR product as well as the backbone vector pTrip ${ }^{53}$ were digested separately with $\mathrm{XbaI} / \mathrm{XhoI}$ and resulting backbone and insert were ligated together to form the final construct.

Next HepG2 cells were transduced with a hNTCP-eGFP lentivirus. Lentivirus was generated by Xtremegene (Roche Applied Science, Indianapolis, IN) mediated co-transfection of $293 \mathrm{~T}$ cells with plasmids encoding (1) a minimal HIV pTRIP with hNTCP-eGFP transgene, (2) gag-pol from HIV $^{53}$ and (3) appropriate viral glycoproteins (VSV-G) ${ }^{53}$. Pseudoparticle-containing supernatants were harvested at 24 and $48 \mathrm{~h}$, pooled and filtered $(0.45 \mu \mathrm{m}$ pore size Millipore, Darmstadt, Germany). Pseudoparticle infections were performed in the presence of $4 \mu \mathrm{g} / \mathrm{ml}$ polybrene. After 3 days cells were then single cell sorted using a Bio-Rad S3 Cell Sorter (Bio-Rad, Hercules, CA) into a collagen coated 96-well plate. Cells were expanded and assessed for hNTCP-eGFP expression using a LSRII Multi-Laser Analyzer (BD, Franklin Lakes NJ) at the Princeton flow cytometry core facility.

HBcAg FACS assay. To assess the susceptibility of hNTCP-eGFP HepG2 clones to HBV infection, cells that had been challenged with HBV were first trypsinized and then fixed with FACS fixation buffer (1\% PBS, 1\% PFA) for 20 min at RT. After fixation, cells were centrifuged and re-suspended in permeabilization buffer ( $1 \%$ FBS, $0.1 \%$ saponin, in $1 \times$ PBS $)$ for $20 \mathrm{~min}$ at RT. After permeabilization, cells 
were again centrifuged and were re-suspended with $50 \mathrm{ul}$ of $\mathrm{HBcAg}$ primary antibody (1:200 diluted in permeabilization buffer; $\mathrm{HBcAg}$ goat-anti-mouse (Fisher Scientific, cat\# MA7609 Waltham, MA) and incubated for $30 \mathrm{~min}$ at $4{ }^{\circ} \mathrm{C}$. After the incubation cells were washed twice with FACS Buffer ( $1 \times$ PBS, $1 \% \mathrm{FBS})$. Cells were then re-suspended and incubated with an Alexa 647 anti-mouse secondary antibody (1:250 dilution in permeabilization buffer; Fisher Scientific, Waltham, MA) for $30 \mathrm{~min}$ at $4{ }^{\circ} \mathrm{C}$. Cells were then washed twice with FACS buffer to remove any excess secondary antibody and were then run on a LSRII Multi-Laser Analyzer (BD, Franklin Lakes, NJ) at the Princeton flow cytometry core facility.

\section{Generation of self-assembling primary hepatocyte co-cultures (SACC-PHHs).} Cryopreserved human hepatocytes were obtained from Bioreclamation IVT Inc. (Westbury, NY) [Hurel lot ID = vender ID: Hu1003 = JMG, Hu1007 = YMD, Hu1010 $=$ TLQ], ThermoFisher Scientific (Waltham, MA) [Hu1004 = HU1552], Sekisui Xenotech LLC (Kansas City, KS) [Hu1008 = 1410235], and Corning Inc. (Corning, NY) [Hu1002 = BD304, Hu1013= BD317].

The co-culture model consists of a mixture of human hepatocytes and non-parenchymal mouse embryonic fibroblast 3T3-J2 cells (American Tissue Culture Collection, ATCC ${ }^{\circledR}$ Number: CCL-92 ${ }^{\mathrm{TM}}$, Manassas, VA) ${ }^{19,} 28-30$. Cryopreserved hepatocytes were removed from liquid nitrogen and thawed in a water bath at $37^{\circ} \mathrm{C}$. Hepatocytes were transferred to a $50 \mathrm{ml}$ conical tube containing $20 \mathrm{ml}$ plating medium (Hurel PlatinumHeps plating medium ${ }^{\mathrm{m}}{ }^{\mathrm{t}}$, Hurel Corporation, New Brunswick, NJ), and centrifuged at $150 \mathrm{xg}$ for $10 \mathrm{~min}$ at room temperature. After removing the supernatant, the cells were re-suspended in Hurel Platinum Heps plating medium ${ }^{\text {st }}$ and cell number as well as cell viability were assessed using trypan blue exclusion. Mouse embryonic fibroblast 3T3-J2 cells were cultured in DMEM (Inoza, Walkersville, MD) supplemented with $10 \%$ heatinactivated fetal bovine serum, $200 \mathrm{U} / \mathrm{ml}$ penicillin/streptomycin. Cells were maintained at $37^{\circ} \mathrm{C}$ in a $5 \% \mathrm{CO}_{2}: 95 \%$ air-humidified atmosphere until used for experimental plating. On plating day, cells were detached from the plate surface using trypsin $(0.25 \%)$, suspended in $15 \mathrm{ml}$ DMEM medium and centrifuged at $200 \mathrm{x} g$ for $5 \mathrm{~min}$ at room temperature. After removing the supernatant, the cells were re-suspended in plating medium (Hurel PlatinumHeps $\mathrm{s}^{\mathrm{m}}$, Hurel Corporation, New Brunswick, NJ) and cell number and viability were determined using trypan blue exclusion.

All co-cultures were plated on collagen type-I coated, tissue culture treated plates 96-well and 24 well (Corning Inc, Corning NY). Hepatocytes were seeded at a seeding density of 30,000 and 188,000 hepatocytes in each well of a 96-well and 24-well plate, respectively. 3T3-J2 cells were added the next day at 15,000 and 90,000 in each well of well of a 96-well and 24-well plate, respectively. Hurelhuman $^{\mathrm{nt}}-24$ and Hurelhuman ${ }^{\mathrm{m}}-\mathrm{9}$-96 SACC-PHH are distributed by the Hurel Corporation (New Brunswick, NJ). Cells were maintained in $500 \mu \mathrm{l}$ for 24 -well plates and $150 \mu \mathrm{l}$ for 96-well plates, in Hurel PlatinumHeps maintenance medium ${ }^{\mathrm{mw}}$, (Hurel Corporation, New Brunswick, NJ). Medium was replaced every 2 days. The cells were co-cultured at $37{ }^{\circ} \mathrm{C}$ in a $5 \% \mathrm{CO}_{2}$ for 10 days prior to $\mathrm{HBV}$ infections.

Characterization of hepatocyte function. All experiments were performed in 96-well tissue culture treated plates with a compound incubation volume of $100 \mu \mathrm{l}$. On the day of the experiment, cultures were incubated with $5 \mu \mathrm{M}$ of midazolam, $20 \mu \mathrm{M}$ dextromethorphan, or $20 \mu \mathrm{M}$ of tolbutamide (Sigma, Missouri, USA) prepared in dosing medium (Hurel Corporation, New Brunswick, NJ) at $37^{\circ} \mathrm{C}$ and $5 \% \mathrm{CO}_{2}$. Incubations were stopped after $1 \mathrm{~h}$ and metabolite formation was monitored. Metabolites were assayed for 1-OH midazolam, dextrorphan, and 4-OH tolbutamide. These are indicative of CYP3A4, CYP2D6, and CYP2C9, respectively. The experiment was terminated by removing $100 \mu \mathrm{l}$ of supernatants which were immediately frozen at $-20^{\circ} \mathrm{C}$.

Formation of metabolites was measured using liquid chromatography-mass spectrometry (LC-MS)/MS at Hurel's facilities (New Brunswick, NJ). Samples were centrifuged at $500 \mathrm{xg}$ for $10 \mathrm{~min}$ before injecting $10 \mu \mathrm{l}$ of each sample. The LC-MS/ MS system comprised a Shimadzu LC-10ADvp pump (Shimadzu, Columbia, MD), SIL-HTS autosampler (Shimadzu, Columbia, MD), and an API 4000 mass spectrometer with a Turbo Ion Spray probe (Applied Biosystems/MDS SCIEX, Ontario, Canada). The separation of compounds was achieved using a reversed stationary phase (Advantage ARMOR C-18, $5 \mathrm{~mm}, 30.0-2.1 \mathrm{~mm}$, Analytical Sales and Services, Inc., Pompton Plains, NJ). A fast gradient using mobile phases of $0.1 \%$ formic acid in acetonitrile and water with $0.1 \%$ formic acid along with switching valves and pumps was used for analysis. Phenomenex C18 Synergi $50 \times 2.00 \mathrm{~mm}$ was used as the analytical column.

Collected medium samples were analyzed for urea concentrations, via a modified Berthelot reaction where phenol is replaced by salicylic acid, using a commercially available assay kit (Stanbio Enzymatic Urea Nitrogen (BUN) Procedure no. 2050) scaled down for use in a 96-well plate. Absorbance was read in a Tecan Ultra 384 microplate reader at $600 \mathrm{~nm}$.

Production of cell-culture-derived HBV. HepG2.2.15 cells $^{7}$ were grown in media containing tetracycline until they reached a confluency of $100 \%$. At this time media was changed to DMEM F12 media supplemented with 10\% FBS, $1 \%$ Pen/Strep. Media from the HepG2.2.15 culture was collected every 2 to 3 days for approximately 4 weeks. The collected media was sterile filtered through a $0.22 \mu \mathrm{m}$ filter (Millipore, Darmstadt, Germany) and was then concentrated ca. 100-fold using a stir cell concentrator (Millipore, Darmstadt, Germany). After concentration, the virus was run over a $5 \mathrm{~mL}$ HiTrap heparin column (GE, Fairfield, CA) to further concentrate and purify infectious virus particles from non-infectious sub-viral particles. Concentrated virus was applied to a heparin column, which was washed with 5-column volumes of wash buffer $(20 \mathrm{mM}$ phosphate buffer, $50 \mathrm{mM} \mathrm{NaCl}, \mathrm{pH}=\sim 7$ ). Afterwards, the virus was eluted with elution buffer ( $20 \mathrm{mM}$ phosphate buffer, $2 \mathrm{M} \mathrm{NaCl}, \mathrm{pH}=\sim 7)$. Once all virus was eluted, the viral stock was dialyzed using a dialysis cassette (Millipore, Darmstadt, Germany). After dialysis, virus was aliquoted into cryovial tubes and cryopreserved at $-80^{\circ} \mathrm{C}$ until use.

Purification of HBV from patient plasma samples. Cryopreserved plasma samples from de-identified, chronic HBV carriers were kindly provided by Susan Stramer (American Red Cross, Gaithersburg, MD). To purify infectious HBV virions and remove coagulation factors the patient plasma samples were loaded onto a $1 \mathrm{ml}$ HiTrap heparin column (GE, Fairfield, CA). The samples once loaded were then washed with 2-column volumes worth of wash buffer $(20 \mathrm{mM}$ phosphate buffer, $50 \mathrm{mM} \mathrm{NaCl}, \mathrm{pH}=\sim 7$ ). This helped aid in the removal of non-infectious sub-viral particles as well as remove some of the coagulation factors present in the patient plasma. The infectious virus was then eluted using elution buffer ( $20 \mathrm{mM}$ phosphate buffer, $2 \mathrm{M} \mathrm{NaCl}, \mathrm{pH}=\sim 7$ ). Once the purified infectious HBV was isolated it was dialyzed using a $3 \mathrm{ml}$ dialysis cassette (Millipore, Darmstadt Germany) in sterile $1 \times \mathrm{PBS}$. After dialysis, virus was stored at $4^{\circ} \mathrm{C}$ until use $24 \mathrm{~h}$ later.

HBV infections. HBV infections of SACC-PHHs, HepG2 overexpressing hNTCP, and un-modified HepG2 cells were performed as follows. HBV infections with tissue culture-derived HBV from HepG2.2.15 cells was used at a MOI of 4000 unless indicated otherwise, in the presence of $4 \%$ polyethylene glycol (PEG) 8000 (Sigma-Aldrich, St Louis, MO) 0.5\% dimethylsulfoxide (DMSO, Sigma-Aldrich, St. Louis, MO).

For HBV infections with purified patient plasma samples HepG2 cells overexpressing hNTCP were challenged with either $7.5,15$, or $30 \%(\mathrm{v} / \mathrm{v})$ patient plasma per well. SACC-PHHs were challenged with $30 \%(\mathrm{v} / \mathrm{v})$ patient plasma per well. Regardless, for the infections, the medium of all cells was supplemented with $\mathrm{MgCl}_{2}(6 \mathrm{mM})$, and $\mathrm{CaCl}_{2}(9 \mathrm{mM})$, and $100 \mu \mathrm{M}$ heparin in order to prevent coagulation.

For monoculture infections of HU1003 the same viral stock of tissue-derived HBVcc was used as for the SACC-PHH HU1003 for direct comparison purposes. The monocultures were plated and the following day a pre-treatment with $0.5 \%$ DMSO was started. On day 2, post plating the cells were challenged with an MOI of 4000 virions for $18 \mathrm{~h}$. After, challenge the inoculum was removed by washing the cells five times with maintenance media. Fresh maintenance media containing $0.5 \%$ DMSO was added. The media was changed every 2 days. Cells were harvested on day 8 post $\mathrm{HBV}$ infection.

Human albumin ELISA. Chromatographically purified human albumin was obtained from MP Biomedicals (catalogue \#2191349, Santa Ana, CA) and horseradish peroxidase-conjugated goat IgG to human albumin was obtained from Bethyl Labs (catalogue \# A80-129P, Montgomery, TX). Following completion of the desired infection and treatment period, serum albumin content was quantified by competitive ELISA. All 96-well and 24-well plates were assayed in an identical manner.

HBV surface antigen ELISA. Detection and quantification of HBsAg levels was performed by ELISA according to the manufacturer's instructions (GS HbsAg EIA 3.1, Bio-Rad, Hercules, CA). Briefly, a $100 \mu \mathrm{l}$ sample of a 1:20 dilution of supernatant was prepared in 1x PBS was used in lieu of undiluted supernatant. Absorbance was read at $450 \lambda$ on the BertholdTech TriStar (Bad Wildbad, Germany).

HBV envelope antigen ELISA. Detection and quantification of HbeAg levels was performed by ELISA according to the manufacturer's instructions (Abnova, Taipei, Taiwan). Briefly, a $100 \mathrm{ul}$ sample of 1:10 diluted supernatant was used in lieu of undiluted supernatant. Absorbance was read at $450 \lambda$ on the BertholdTech TriStar (Bad Wildbad, Germany).

HBV DNA isolation from supernatants. HBV DNA was isolated following the Qiamp MinElute Virus Spin Kit (50), (Qiagen, Hilden, Germany). HBV DNA was eluted in 60 , and $5 \mu \mathrm{l}$ was used per well in the HBV DNA quantitative PCR (qPCR) reaction.

Total HBV DNA isolation and quantification from infected cells. To isolate total HBV DNA from HBV challenged SACC-PHHs, 3B10, or HepG2 cells, $300 \mu \mathrm{l}$ (24 well) or $100 \mu \mathrm{l}$ (96-well) of lysis buffer was added, respectively, to the corresponding sample (50 mM Tris-Base, $50 \mathrm{mM}$ EDTA, $1 \%$ SDS, $100 \mathrm{mM} \mathrm{NaCl}$ 
$\mathrm{pH}$ 8.0). The sample was further digested through the addition of $20 \mu \mathrm{l}$ of Proteinase K per sample from a QIAMP DNA mini kit (Qiagen, Hilden, Germany) for an hour at $37^{\circ} \mathrm{C}$. After digestion with Proteinase $\mathrm{K}, 1 \mu \mathrm{l}$ of Rnase A (Sigma Aldrich, St Louis, MO) was added to the lysate and incubated at room temperature for 2 min. Five-hundred microliters of AL lysis buffer (Qiagen, Hilden, Germany) was subsequently added to the solution. The samples were incubated at $70^{\circ} \mathrm{C}$ for 4 $\mathrm{h}$, vortexed every $20 \mathrm{~min}$ to digest the cells completely. Following this step, $500 \mu \mathrm{l}$ of $100 \% \mathrm{EtOH}$ were added and mixed thoroughly by inverting 10 times. This suspension was then applied to a Qiamp DNA mini kit column and centrifuged for $1 \mathrm{~min}$ at $16,000 \mathrm{xg}$ ). The samples were spun again in new tubes for $1 \mathrm{~min}$ at $16,000 \times \mathrm{x}$ to dry. The DNA was then eluted with $50 \mu \mathrm{l}$ of AE buffer and concentrations measured using a Nanodrop spectrophotometer (Thermo Fischer Scientific, Waltham, MA).

A $5 \mu \mathrm{l}$ aliquot of HBV DNA isolated from lysed cells was used per reaction well. To amplify HBV DNA the following primers and probes were used: CCGTCTGTGCCTTCTCATCTG (forward primer), AGTCCAAGAGTCCTCTT ATGTAAGACCTT (reverse primer), and probe FAM-CCGTGTGCACTTCGCT TCACCTCTGC-TAMRA ${ }^{22}$. Primers were kept at a concentration of $600 \mathrm{nM}$ and probe at $300 \mathrm{nM}$ final concentration in the reaction. A master mix was created containing $2 \times$ TaqMan reaction mix (Applied Biosystems, Foster City, CA), primer/probe mix and $\mathrm{ddH}_{2} \mathrm{O}$. The master mix was then applied with the samples to the respective wells. Five microliters of the standards and the samples were added to the respective wells. The following PCR program was run on a Step One Plus qPCR machine (Life Technologies, Carlsbad, CA): $50^{\circ} \mathrm{C}$ for $5 \mathrm{~min}, 95^{\circ} \mathrm{C}$ for 10 min, followed by 40 cycles of $95^{\circ} \mathrm{C}$ for $15 \mathrm{~s}, 56^{\circ} \mathrm{C}$ for $40 \mathrm{~s}$, and $72^{\circ} \mathrm{C}$ for $20 \mathrm{~s}$. Lastly, a melt curve was performed at $95^{\circ} \mathrm{C}$ for $10 \mathrm{~s}, 65^{\circ} \mathrm{C}$ for $10 \mathrm{~s}, 50^{\circ} \mathrm{C}$ for $5 \mathrm{~s}$, and $95^{\circ} \mathrm{C}$ for $5 \mathrm{~s}$.

HBV pgRNA isolation and quantification from infected primary hepatocytes. SACC-PHHs were lysed with $350 \mu$ RLT buffer (Qiagen RNAeasy kit, Qiagen, Hilden Germany) supplemented with 2-Mercaptoethanol for $10 \mathrm{~min}$ at RT. The cells were then pipetted into an RNase free Eppendorf tube. The cell suspensions were then passed through a $261 \frac{1}{2}$ gauge needle five times in order to facilitate cell lysis. Once completed, the manufacturers protocol for the Qiagen RNAeasy kit (Qiagen, Hilden, Germany) was followed except for elution where the sample was eluted twice once with $50 \mu \mathrm{l}$ of Rnase free water and then addition $30 \mu \mathrm{l}$.

To quantify HBV pgRNA a modified iTaq Universal SYBR Green One-Step qPCR kit (BioRad, Hercules, CA) protocol was used. A primer mix with each primer at $3 \mu \mathrm{M}$ was created with the forward primer GAGTGTGGATTCG CACTCC and the reverse primer GAGGCGAGGGAGTTCTTCT ${ }^{2}$. A master mix was created as follows per reaction: $5 \mu$ of SYBR mix, $0.125 \mu \mathrm{l}$ of RT, $1 \mu$ l of primer mix, and $1.875 \mu$ of $\mathrm{ddH}_{2} \mathrm{O}$. The following cycling time was used: reverse transcription and amplification step at $50^{\circ} \mathrm{C}$ for $10 \mathrm{~min}$ and $95^{\circ} \mathrm{C}$ for $1 \mathrm{~min}$; 40 cycles of $95^{\circ} \mathrm{C} 15 \mathrm{~s}$, and $60^{\circ} \mathrm{C}$ for $1 \mathrm{~min}$. The melt curve was performed at $95^{\circ} \mathrm{C}$ for $5 \mathrm{~s}, 65^{\circ} \mathrm{C}$ for $5 \mathrm{~s}, 95^{\circ} \mathrm{C}$ for $15 \mathrm{~s}$, and $50^{\circ} \mathrm{C}$ for $5 \mathrm{~s}$.

HBV cccDNA isolation and quantification from infected primary hepatocytes. A $25 \mu \mathrm{l}$ aliquot of the respective total HBV DNA sample isolated from cell lysate was digested with $1 \mu \mathrm{l}$ plasmid-safe DNAse (Epicentre, E3101K, Madison, WI) to destroy all chromosomal DNA along with any linear form of HBV DNA. According to the manufacturer's instructions, the reaction mix was incubated at $37^{\circ} \mathrm{C}$ for $30 \mathrm{~min}$ to $1 \mathrm{~h}$ in order to digest the samples. Following the digestion, plasmid-safe DNase was heat inactivated by incubating the samples at $70^{\circ} \mathrm{C}$ for $30 \mathrm{~min}$. The cccDNA was then purified using a DNA clean up and concentration kit (Zymo, Irvine, CA), eluted in $30 \mu \mathrm{l}$ of sterile $\mathrm{ddH}_{2} \mathrm{O}$, and the residual amount of DNA quantified using a Nanodrop spectrophotometer. This resulted in a 1-1.5 log drop in overall DNA concentration. Samples were either used immediately for HBV cccDNA quantification by qPCR or were stored at $-20^{\circ} \mathrm{C}$.

Quantitation of HBV cccDNA was performed as follows. A $5 \mu$ laliquot of HBV DNA either isolated from mouse serum or from liver DNA was used per reaction well. We used the following primers and probes: GTCTGTGCCTTCTCATCTGC (forward primer), AGTAACTCCACAGTAGCTCCAAATT (reverse primer), and probe FAM-TTCAAGCCTCCAAGCTGTGCCTTGGGTGGC-TAMRA. The final concentration of primers was $0.9 \mu \mathrm{M}, 0.2 \mu \mathrm{M}$ probe, and $4 \%$ DMSO. The following qPCR cycling was used: $95^{\circ} \mathrm{C}$ for $10 \mathrm{~min}$, followed by 50 cycles of $95^{\circ} \mathrm{C}$ for $15 \mathrm{~s}$, and $61^{\circ} \mathrm{C}$ for $1 \mathrm{~min}$.

Immunofluorescence imaging of $\mathbf{H b c A g}$ in infected primary hepatocytes. HBV infected SACC-PHHs were washed once with sterile $1 \times$ phosphate-buffered saline (PBS, Life technologies, Carlsbad, CA) and then fixed for 20 min with $4 \%$ (w/v) paraformaldehyde (PFA, Sigma-Aldrich, St. Louis, MO) at room temperature (RT). After fixation, the cells were washed three times with sterile $1 \times$ PBS. Cells were then incubated for $30 \mathrm{~min}$ in blocking buffer (10\% bovine serum albumin in sterile $1 \times$ PBS, Sigma-Aldrich, St Louis, MO). After 30 min the primary anti-HBcAg antibody (DAKO rabbit polyclonal, catalog \#B0586, Santa Clara, CA) was added at a 1:1600 dilution for $1 \mathrm{~h}$. After the $1 \mathrm{~h}$ incubation with the primary antibody the cells were washed five times with $1 \times$ PBS. The secondary was then added (Anti-rabbit-Alexa555 1:1000, Fisher Scientific, Waltham, MA) along with the nuclear Hoechst dye (1:10,000, Sigma-Aldrich, St Louis, MO and the cells were incubated for an additional hour. After incubation, the cells were washed five times with $1 \times$ PBS and then had $300 \mu \mathrm{l}$ of sterile $1 \times$ PBS added and the cells were stored at $4^{\circ} \mathrm{C}$ until imaging.

Cloning, expression, and purification of hTDP2. The coding sequence of human TDP2 was PCR amplified from a hTDP2 expression plasmid (NM_016614.2) with Q5 (NEB, Ipswich, MA) and inserted into a pQLinkH (Addgene, plasmid \#13667) expression plasmid via restriction digest with BamHI and HindIII and ligated ON at $16^{\circ} \mathrm{C}$. The sequence of the $N$-terminally $7 \mathrm{x}$ His-tagged TDP 2 was confirmed by DNA sequencing. BL21-DE3 Rosetta cells (EMD Millipore, Billerica, MA) were transfected with the TDP2 expression plasmid and grown in LB medium at $37^{\circ} \mathrm{C}$ until reaching an OD600 of 0.6. Protein expression was induced by the addition of $1 \mathrm{mM}$ IPTG (Sigma-Aldrich, St Louis, MO) for $16 \mathrm{~h}$ at $30^{\circ} \mathrm{C}$. The cells were collected via centrifugation and frozen at $-20^{\circ} \mathrm{C}$ until purified. To purify the TDP2, the pellet was defrosted and re-suspended in $50 \mathrm{ml}$ native binding buffer $\left(500 \mathrm{M} \mathrm{NaCl}\right.$ and $50 \mathrm{mM} \mathrm{NaH} \mathrm{PO}_{4}, \mathrm{pH} 8.0$ ) with $100 \mathrm{mg}$ lysozyme and incubated on ice for $30 \mathrm{~min}$. Cells were sonicated with $6 \times 10 \mathrm{~s}$ bursts at high intensity with cooling in between. DNase I (Worthington, Columbus, OH) was added at $5 \mu \mathrm{g} / \mathrm{ml}$ and incubated on ice for $15 \mathrm{~min}$. Lysate was spun at $3000 \mathrm{xg}$ for $15 \mathrm{~min}$ and supernatant transferred to clean tube. In all, $1.5 \mathrm{~mL}$ Ni NTA resin (Life Technologies, Carlsbad, CA) was transferred to $15 \mathrm{ml}$ column and equilibrated with native binding buffer. Supernatant was run over column twice, and resin was washed $3 \times 10 \mathrm{ml}$ with native wash buffer (native binding buffer with $20 \mathrm{mM}$ imidazole). Resin was eluted with $250 \mathrm{mM}$ imidazole in native binding buffer and collected in $1.5 \mathrm{ml}$ fractions. Fractions were analyzed by Sodium dodecyl sulfate polyacrylamide gel electrophoresis ( $10 \%$ acrylamide gel) followed by Coomassie staining. In addition, western blotting was performed using an anti-His antibody (Millipore, clone HIS.H8, catalog \#05-949, Billerica, MA) at 1:1000 dilution and visualized with a LiCor Odyssey. Pure fractions were combined and dialyzed twice against native binding buffer using a $10 \mathrm{kDa}$ dialysis cassette (Pierce, Waltham MA) before being further purified via size exclusion chromatography using an S75 16/60 column. Pure protein was then lyophilized and stored at $-80^{\circ} \mathrm{C}$ until further use.

In vitro fluorescence hTDP2 inhibition assay. To test the activity of hTDP2 and to corroborate the inhibitory effect of JK-3-121 and SV-F-153 hTDP2 inhibitors, we performed a fluorescence based assay as previously described ${ }^{40}$. First, a 5'-methylumbelliferon (MUP) - phosphodiester bond 5'-GTAATTCTTAAGT TG-3' oligo was synthesized (IDT, San Jose, CA). The MUP- GTAATTCTTAAGTTG and lyophilized hTDP2 was solubilized in substrate buffer $(50 \mathrm{mM}$ Tris- $\mathrm{HCl}, 80 \mathrm{mM} \mathrm{KCl}, 2 \mathrm{mM}$ EDTA, $1 \mathrm{mM}$ DTT, $40 \mathrm{ug} / \mathrm{mL}$ BSA, 10\% DMSO, $5 \mathrm{mM} \mathrm{MgCl}, \mathrm{pH}=8)$. For each reaction hTDP2 was at a final concentration of $100 \mathrm{nM}$, and the MUP-GTAATTCTTAAGTTG oligo was at a concentration of $0.5 \mu \mathrm{M}$, in a total reaction volume of $200 \mu \mathrm{l}$ of substrate buffer. The JK-3-121 and SV-F-153 inhibitors were added to the respective wells at 10, 1, 100, and $10 \mathrm{nM}$, respectively, and incubated for $30 \mathrm{~min}$ at room temperature. A control condition of hTDP2 was used without either inhibitor being present. All conditions were run in quadruplicate, in a black $\mu$ Clear 96-well plate (Greiner-bio-One, Kremsmünster, Austria), in a SpectraMAX 96-well plate reader (Molecular Devices, Sunnyvale, $C A$ ) with excitation $=355 \mathrm{nM}$, and emission $=460 \mathrm{nM}$

Generation of PreS1-fluorescein isothiocyanate (FITC) and inactive PreS1 peptides. The PreS1-FITC peptide (Myr-GTNLSVPNPLGFFPDHQLDPAFGANSNNPDWDFNPNKDHWPEANQVGK-FITC) was purchased from (Life Tein, Somerset, NJ). The inactive PreS1 peptide variant containing a quintuplet alanine amino acids at positions 10-14 was synthesized using Fmoc solid phase synthesis. To avoid aspartimide formation the Fmoc deprotection was carried out with $20 \%$ Piperidine in dimethylformamide (DMF) and $0.1 \mathrm{M} \mathrm{HOBT}$ at room temperature. Amino acid coupling was performed at $50^{\circ} \mathrm{C}$ using baseless DIC/Oxyma double coupling. Myristic acid was coupled to the $N$-terminus for $18 \mathrm{~h}$ at room temperature using 10 equiv. Myristic acid, 10 equiv. PyAOP and 20 equiv. DIEA in DMF. The crude peptide was cleaved from the resin $(95 \%$ trifluoroacetic acid (TFA), 2.5\% TIS, and 2.5\% $\mathrm{H}_{2} \mathrm{O}$ ), precipitated with diethylether and purified using preparative high-performance liquid chromatography $(0-95 \% \mathrm{MeCN}$ in 60 $\mathrm{min})$. The identity of the peptide was confirmed by mass spectrometry: Expected $5229.54 \mathrm{Da}$, Found $=5229.84 \mathrm{Da}$. The control peptide sequence was as follows Myr-GQNLSTSNPA

AAAADHQLDPAFRANTANPDWDFNPNKDTWPDANKVG-CONH 2.

PreS1 prophylactic inhibition assay. Plated SACC-PHHs (mixed donor HU1007) were first incubated for $2 \mathrm{~h}$ with either a PreS1-derived peptide conjugated to a FITC label or with an inactive PreS1 variant that contains a quintuplet alanine amino acids at positions 10-14. After the $2 \mathrm{~h}$ incubation, the cells were then challenged with $\mathrm{HBV}(\mathrm{MOI}=4000)$ in the presence of $0.5 \% \mathrm{DMSO}$, and $4 \% \mathrm{PEG}$ 8000 for $18 \mathrm{~h}$. At the conclusion of $18 \mathrm{~h}$, the cells were then washed five times with media and fresh maintenance media contain 0.5\% DMSO was then added with the corresponding concentration of PreS1 or control peptide $(1 \mu \mathrm{M}, 100 \mathrm{nM}, 10 \mathrm{nM}$, and $1 \mathrm{nM})$. Every 2 days, the media was replaced with maintenance media containing $0.5 \%$ DMSO and the corresponding concentration of peptide. 
Supernatants were run for HBsAg ELISA to determine if inhibition of HBV infection had occurred. In addition, a control condition of SACC-PHH's only challenged with $\mathrm{HBVcc}$ without any peptide inhibitor was also performed.

Drug inhibition assays. Drug treatment with TDP2 inhibitors JK-3-121 and SF-V- $153^{40}$ or with entecavir (ETV, Sigma-Aldrich, St Louis, MO) were performed in 96-well plates seeded with either PHH's or hNTCP-eGFP HepG2 cells. TDP2 inhibitors were solubilized in $100 \%$ DMSO and were stored at $-20^{\circ} \mathrm{C}$ while ETV was solubilized in sterile $1 \times$ PBS. Prior to drug treatment, cells were treated with $0.5 \%$ DMSO for $24 \mathrm{~h}$ and then were challenged with HBV derived from HepG2.2.15 cells that had been heparin column purified. Once persistent HBV infection was established (day 16) drug treatment was started. A series of concentrations was used for each drug. For TDP2 inhibitors JK-3-121 and SV-F-153 concentrations of $1 \times 10^{4}, 1 \times 10^{3}, 1 \times 10^{2}$, and $10 \mathrm{nM}$, stocks of each TDP2 inhibitor were created in order to maintain the same level of DMSO. ETV was used at final concentrations of 250,125 , and $25 \mathrm{nM}$. Drug treatment was performed over 18 days during which the inhibitors were freshly supplied every 2 days at each media change with monitoring of $\mathrm{HbsAg}$ and hAlb levels over this period of time. At the end of the 18 days, cells were lysed with lysis buffer (50 mM Tris-Base, $50 \mathrm{mM}$ EDTA, $1 \%$ SDS, $100 \mathrm{mM} \mathrm{NaCl} \mathrm{pH} \mathrm{8.0)} \mathrm{or} \mathrm{with} \mathrm{Qiagen} \mathrm{RLT} \mathrm{supplemented}$ with 2-Mercaptoethanol for 10 min at RT. Total HBV DNA, pgRNA, and cccDNA were quantified. As a control, a set of wells were only challenged with HBV and had no drug treatment administered over the course of the experiment. Ever condition was performed in sextuplets.

Prophylactic drug treatment with TDP2 inhibitors JK-3-121 and SF-V-153 or with ETV was performed in 96-well plates seeded with either PHH's or hNTCPeGFP HepG2 cells. TDP2 inhibitors were solubilized in 100\% DMSO and were stored at $-20^{\circ} \mathrm{C}$ while ETV was solubilized in sterile $1 \times$ PBS. 1 day prior to HBV challenge cells were treated with respective concentration of either TDP2 inhibitors or ETV. Cells were then challenged with HBV derived from HepG2.2.15 cells that were heparin column purified in the presence of the respective drug. Every 2 days, media was collected and new media with the respective concentration of inhibitor was added in order to maintain a constant level of drug throughout the experiment. For TDP2 inhibitors, JK-3-121 and SV-F-153 concentrations of $1 \times 10^{4}, 1 \times 10^{3}$, $1 \times 10^{2}$, and $10 \mathrm{nM}$, stocks of each TDP2 inhibitor were created in order to maintain the same level of DMSO. ETV was used at final concentrations of 250, 125, and 25 $\mathrm{nM}$. Drug treatment was performed over 34 days for SACC-PHHs and for 19 days for hNTCP-eGFP HepG2 cells with monitoring of HbsAg and hAlb levels over this period of time. At the end of the 34 or 19 days, cells were lysed with lysis buffer (50 mM Tris-Base, $50 \mathrm{mM}$ EDTA, $1 \%$ SDS, $100 \mathrm{mM} \mathrm{NaCl} \mathrm{pH} \mathrm{8.0)} \mathrm{or} \mathrm{with} \mathrm{Qiagen}$ RLT supplemented with 2-Mercaptoethanol for $10 \mathrm{~min}$ at RT. Total HBV DNA, pgRNA, and cccDNA were quantified. As a control, a set of wells were only challenged with HBV and had no drug treatment administered over the course of the experiment. Ever condition was performed in sextuplets.

Data availability. The data that support the findings of this study are available from the corresponding author upon request.

Received: 2 March 2017 Accepted: 8 June 2017

Published online: 25 July 2017

\section{References}

1. Ni, Y. et al. Hepatitis B and D viruses exploit sodium taurocholate cotransporting polypeptide for species-specific entry into hepatocytes. Gastroenterology 146, 1070-1083 (2014)

2. Yan, H. et al. Sodium taurocholate cotransporting polypeptide is a functional receptor for human hepatitis B and D virus. eLife 1, e00049 (2012).

3. Li, W. \& Urban, S. Entry of hepatitis B and hepatitis D virus into hepatocytes: basic insights and clinical implications. J. Hepatol. 64, S32-S40 (2016).

4. Winer, B. Y. \& Ploss, A. Determinants of hepatitis B and delta virus host tropism. Curr. Opin. Virol. 13, 109-116 (2015).

5. Guo, H. et al. Characterization of the intracellular deproteinized relaxed circular DNA of hepatitis B virus: an intermediate of covalently closed circular DNA formation. J. Virol. 81, 12472-12484 (2007).

6. Seeger, C. \& Mason, W. S. Hepatitis B virus biology. Microbiol. Mol. Biol. Rev. 64, 51-68 (2000).

7. Sells, M. A., Chen, M. L. \& Acs, G. Production of hepatitis B virus particles in Hep G2 cells transfected with cloned hepatitis B virus DNA. Proc. Natl Acad. Sci. USA 84, 1005-1009 (1987).

8. Ladner, S. K. et al. Inducible expression of human hepatitis B virus (HBV) in stably transfected hepatoblastoma cells: a novel system for screening potential inhibitors of HBV replication. Antimicrob. Agents Chemother. 41, 1715-1720 (1997).

9. Gripon, P. et al. Infection of a human hepatoma cell line by hepatitis B virus. Proc. Natl Acad. Sci. USA 99, 15655-15660 (2002).
10. Wilkening, S., Stahl, F. \& Bader, A. Comparison of primary human hepatocytes and hepatoma cell line Hepg2 with regard to their biotransformation properties. Drug Metab. Dispos. 31, 1035-1042 (2003).

11. Shimizu, Y. K. et al. Further studies by immunofluorescence of the monoclonal antibodies associated with experimental non- $A$, non-B hepatitis in chimpanzees and their relation to D hepatitis. Hepatology 6, 1329-1333 (1986).

12. Gripon, P., Diot, C. \& Guguen-Guillouzo, C. Reproducible high level infection of cultured adult human hepatocytes by hepatitis B virus: effect of polyethylene glycol on adsorption and penetration. Virology 192, 534-540 (1993).

13. Gripon, P. et al. Hepatitis B virus infection of adult human hepatocytes cultured in the presence of dimethyl sulfoxide. J. Virol. 62, 4136-4143 (1988).

14. Ochiya, T. et al. An in vitro system for infection with hepatitis B virus that uses primary human fetal hepatocytes. Proc. Natl Acad. Sci. USA 86, 1875-1879 (1989).

15. Galle, P. R. et al. In vitro experimental infection of primary human hepatocytes with hepatitis B virus. Gastroenterology 106, 664-673 (1994).

16. Zhou, M. et al. Long-term maintenance of human fetal hepatocytes and prolonged susceptibility to HBV infection by co-culture with non-parenchymal cells. J. Virol. Methods 195, 185-193 (2014).

17. Thomas, E. \& Liang, T. J. Experimental models of hepatitis B and C-new insights and progress. Nat. Rev. Gastroenterol. Hepatol. 13, 362-374 (2016).

18. Verrier, E. R., Colpitts, C. C., Schuster, C., Zeisel, M. B., Baumert, T. F. Cell culture models for the investigation of hepatitis B and D virus infection. Viruses 8, E261 (2016).

19. Kidambi, S. et al. Oxygen-mediated enhancement of primary hepatocyte metabolism, functional polarization, gene expression, and drug clearance. Proc. Natl Acad. Sci. USA 106, 15714-15719 (2009).

20. Khetani, S. R. \& Bhatia, S. N. Microscale culture of human liver cells for drug development. Nat. Biotechnol. 26, 120-126 (2008).

21. Bhatia, S. N., Balis, U. J., Yarmush, M. L. \& Toner, M. Effect of cell-cell interactions in preservation of cellular phenotype: cocultivation of hepatocytes and nonparenchymal cells. FASEB J. 13, 1883-1900 (1999).

22. Shlomai, A. et al. Modeling host interactions with hepatitis B virus using primary and induced pluripotent stem cell-derived hepatocellular systems. Proc. Natl Acad. Sci. USA 111, 12193-12198 (2014).

23. March, S. et al. A microscale human liver platform that supports the hepatic stages of plasmodium falciparum and vivax. Cell Host Microbe 14, 104-115 (2013).

24. Ploss, A. et al. Persistent hepatitis $C$ virus infection in microscale primary human hepatocyte cultures. Proc. Natl Acad. Sci. USA 107, 3141-3145 (2010).

25. Gripon, P., Cannie, I. \& Urban, S. Efficient inhibition of hepatitis B virus infection by acylated peptides derived from the large viral surface protein. J. Virol. 79, 1613-1622 (2005).

26. Petersen, J. et al. Prevention of hepatitis B virus infection in vivo by entry inhibitors derived from the large envelope protein. Nat. Biotechnol. 26, 335-341 (2008).

27. Koniger, C. et al. Involvement of the host DNA-repair enzyme TDP2 in formation of the covalently closed circular DNA persistence reservoir of hepatitis B viruses. Proc. Natl Acad. Sci. USA 111, E4244-E4253 (2014).

28. Atienzar, F. A. et al. Predictivity of dog co-culture model, primary human hepatocytes and HepG2 cells for the detection of hepatotoxic drugs in humans. Toxicol. Appl. Pharmacol. 275, 44-61 (2014).

29. Bonn, B., Svanberg, P., Janefeldt, A., Hultman, I. \& Grime, K. Determination of human hepatocyte intrinsic clearance for slowly metabolized compounds: comparison of a primary hepatocyte/stromal cell co-culture with plated primary hepatocytes and HepaRG. Drug Metab. Dispos. 44, 527-533 (2016).

30. Chao, P. et al. Prediction of human hepatic clearance using an in vitro plated hepatocyte clearance model. Drug Metab. Lett. 3, 296-307 (2009).

31. Zhou, T. et al. Hepatitis B virus e antigen production is dependent upon covalently closed circular (ccc) DNA in HepAD38 cell cultures and may serve as a cccDNA surrogate in antiviral screening assays. Antiviral. Res. 72, 116-124 (2006).

32. Novik, E., Maguire, T. J., Chao, P., Cheng, K. C. \& Yarmush, M. L. A microfluidic hepatic coculture platform for cell-based drug metabolism studies. Biochem. Pharmacol. 79, 1036-1044 (2010).

33. Hultman, I., Vedin, C., Abrahamsson, A., Winiwarter, S. \& Darnell, M. Use of HmuREL human coculture system for prediction of intrinsic clearance and metabolite formation for slowly metabolized compounds. Mol. Pharm. 13, 2796-2807 (2016).

34. Norder, H., Courouce, A. M. \& Magnius, L. O. Complete genomes, phylogenetic relatedness, and structural proteins of six strains of the hepatitis B virus, four of which represent two new genotypes. Virology 198, 489-503 (1994).

35. Stuyver, L. et al. A new genotype of hepatitis B virus: complete genome and phylogenetic relatedness. J. Gen. Virol. 81, 67-74 (2000).

36. Arauz-Ruiz, P., Norder, H., Robertson, B. H. \& Magnius, L. O. Genotype H: a new Amerindian genotype of hepatitis B virus revealed in Central America. J. Gen. Virol. 83, 2059-2073 (2002). 
37. Sugiyama, M. et al. Influence of hepatitis B virus genotypes on the intra- and extracellular expression of viral DNA and antigens. Hepatology 44, 915-924 (2006).

38. Schulze, A., Schieck, A., Ni, Y., Mier, W. \& Urban, S. Fine mapping of pre-S sequence requirements for hepatitis B virus large envelope protein-mediated receptor interaction. J. Virol. 84, 1989-2000 (2010).

39. Cui, X. et al. Does Tyrosyl DNA phosphodiesterase-2 play a role in hepatitis B virus genome repair? PLoS ONE 10, e0128401 (2015).

40. Marchand, C. et al. Deazaflavin inhibitors of tyrosyl-DNA phosphodiesterase 2 (TDP2) specific for the human enzyme and active against cellular TDP2. ACS Chem. Biol. 11, 1925-1933 (2016).

41. Temel, R. E. et al. Hepatic Niemann-Pick C1-like 1 regulates biliary cholesterol concentration and is a target of ezetimibe. J. Clin. Invest. 117, 1968-1978 (2007).

42. Schwartz, R. E., Fleming, H. E., Khetani, S. R. \& Bhatia, S. N. Pluripotent stem cell-derived hepatocyte-like cells. Biotechnol. Adv. 32, 504-513 (2014).

43. Khetani, S. R., Szulgit, G., Del Rio, J. A., Barlow, C. \& Bhatia, S. N. Exploring interactions between rat hepatocytes and nonparenchymal cells using gene expression profiling. Hepatology 40, 545-554 (2004).

44. Nahmias, Y. et al. A novel formulation of oxygen-carrying matrix enhances liver-specific function of cultured hepatocytes. FASEB J. 20, 2531-2533 (2006).

45. Li, Y. et al. Genome-wide association study identifies 8p21.3 associated with persistent hepatitis B virus infection among Chinese. Nat. Commun. 7, 11664 (2016).

46. Hu, Z. et al. New loci associated with chronic hepatitis B virus infection in Han Chinese. Nat. Genet. 45, 1499-1503 (2013).

47. Dandri, M. et al. Repopulation of mouse liver with human hepatocytes and in vivo infection with hepatitis B virus. Hepatology 33, 981-988 (2001).

48. Lutgehetmann, M. et al. Humanized chimeric uPA mouse model for the study of hepatitis B and D virus interactions and preclinical drug evaluation. Hepatology 55, 685-694 (2012).

49. Volz, T. et al. The entry inhibitor Myrcludex-B efficiently blocks intrahepatic virus spreading in humanized mice previously infected with hepatitis B virus. J. Hepatol. 58, 861-867 (2013).

50. Allweiss, L. et al. Proliferation of primary human hepatocytes and prevention of hepatitis B virus reinfection efficiently deplete nuclear cccDNA in vivo. Gut (in the press).

51. Blank, A. et al. First-in-human application of the novel hepatitis B and hepatitis D virus entry inhibitor myrcludex B. J. Hepatol. 65, 483-489 (2016).

52. Bogomolov, P. et al. Treatment of chronic hepatitis D with the entry inhibitor myrcludex B: First results of a phase Ib/IIa study. J. Hepatol. 65, 490-498 (2016).

53. Ploss, A. et al. Human occludin is a hepatitis $\mathrm{C}$ virus entry factor required for infection of mouse cells. Nature 457, 882-886 (2009).

\section{Acknowledgements}

We would like to thank Robert Schwartz (Weill Cornell Medical College) and members of the Ploss lab, in particular Jenna Gaska and Lei Wei, for critical discussion and edits on the manuscript. We would also like to thank Alexander Goglia and Jared Toettcher for technical assistance in collecting the HAcAg IF images. HepG2.2.15 cells were kindly provided by Christoph Seeger (Fox Chase Cancer Center), HBV + plasma samples by Susan Stramer (American Red Cross) and TDP2 inhibitors by Christophe Marchand and Yves Pommier (National Cancer Institute). This study is supported in part by grants from the National Institutes of Health (R21AI117213 to A.P. and R37GM086868 to T.W.M.), a Burroughs Wellcome Fund Award for Investigators in Pathogenesis (to A.P.) and funds from Princeton University (to A.P.). B.Y.W. is a recipient of F31 NIH/NRSA Ruth L. Kirschstein Predoctoral awarded from the NIAID. F.W. is supported by a German Research Foundation (DFG) postdoctoral fellowship.

\section{Author contributions}

B.Y.W. and A.P. designed and performed experiments, and wrote the manuscript. T.S.H., E.P., B.H., F.W., G.E.L., Am.P., C.C., and A.S. performed experiments. T.W.M. provided infrastructure, significant resources, and edited the manuscript. E.N. performed experiments and edited the manuscript.

\section{Additional information}

Supplementary Information accompanies this paper at doi:10.1038/s41467-017-00200-8

Competing interests: E.P., Am.P., C.C., A.S., and E.N. are employees of the Hurel Corporation of which E.N. is also a stockholder. The remaining authors declare no competing financial interests.

Reprints and permission information is available online at http://npg.nature.com/ reprintsandpermissions/

Publisher's note: Springer Nature remains neutral with regard to jurisdictional claims in published maps and institutional affiliations.

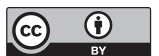

Open Access This article is licensed under a Creative Commons Attribution 4.0 International License, which permits use, sharing, adaptation, distribution and reproduction in any medium or format, as long as you give appropriate credit to the original author(s) and the source, provide a link to the Creative Commons license, and indicate if changes were made. The images or other third party material in this article are included in the article's Creative Commons license, unless indicated otherwise in a credit line to the material. If material is not included in the article's Creative Commons license and your intended use is not permitted by statutory regulation or exceeds the permitted use, you will need to obtain permission directly from the copyright holder. To view a copy of this license, visit http://creativecommons.org/ licenses/by/4.0/.

(C) The Author(s) 2017 